\title{
An Investigation of the Relationship between EFL Reading Comprehension and Intrinsic Motivation
}

A Research extracted from a Thesis Submitted in Partial Fulfilment of the Requirements for the M.A Degree in Education

In

Curriculum and EFL Instruction by

Tamer Nageeb Aaref

Teacher of English as a Foreign Language

Supervised by

\section{Chapter One \\ The Problem and Its Significance}

\section{Introduction}

Reading comprehension is of an outmost importance: it represents the foundation for most students. Students spend much of their time reading and learning information presented in text. Competence of reading comprehension is the main determinant for the success in learning any subject matter. Reading can be equated with comprehension, and that whatever a teacher does, whatever methods and materials are used, comprehension should be the overriding concern as reading comprehension can be said to be the soul of reading.

Reading comprehension is perceiving of the vocabularies which are used in a written text and making a relationship between them to achieve a comprehensive understanding (Becker et al., 2010). Reading comprehension provides the foundation for a substantial amount of learning in education (Mohammadian et al., 2017). Because reading comprehension is so logical in terms 
of academic success, it can be argued that motivating a student to read is essential.

Motivation is considered to be one of the neglected parts of English as a foreign language teaching. Instructors often forget that motivation is the basic part of learners' English language learning activities. If there is no learners' motivation, there is no pulse and no life English classes (Takaloo \& Ahmadi, 2017). Brophy (2010) describes student motivation as the extent to which students will exert time, energy, and attention in various tasks, goals or activities. Therefore, reading motivation is the extent to which students will invest time, energy, and attention in various reading activities. Reading motivation is the interest or desire to read for different purposes (Takaloo \& Ahmadi, 2017).

The connection between motivation and reading comprehension has been investigated by a body of research (Jafari \& Shokrpour, 2012; Schaffner \& Ulferts, 2013; Mermelstein, 2014). In the study conducted by (Jafari \& Shokrpour, 2012) that aimed to investigate the relationship between motivation and reading comprehension, the findings indicated that there was a significant correlation between intrinsic motivation and learners reading development. In fact motivated learners had more eagerness for reading texts.

Among the most important factors that affect reading comprehension is motivation. The correlation between reading motivation and reading comprehension is more than reading comprehension activities and motivation behavior. There were a 
lot of research that examined the relation between motivation and reading comprehension and it looks that there is a direct relationship between reading comprehension and reading motivation (Logan, et al., 2011).

\section{Context of the problem}

It is obvious from the previous introduction that there is a real need to investigate the relationship between reading comprehension and reading motivation from another perspective. All the previous research is directed in one way that is "the effect of reading motivation on reading comprehension". At this point the researcher reached the current study research gap. Therefore, the current study attempts to answer the following question:

\section{Question of the study}

- To what extent is there a relationship between reading comprehension and reading motivation in EFL context?

This main question branches out into the following subquestions:

- To what extent is there a relationship between literal reading comprehension and intrinsic reading motivation in EFL context?

- To what extent is there a relationship between inferential reading comprehension and intrinsic reading motivation in EFL context? 


\section{Aims of the study:}

This study aims at:

- Investigating the relationship between reading comprehension and intrinsic reading motivation between the scores obtained from both reading comprehension test and reading motivation questionnaire.

\section{The Study Hypotheses}

The present study attempts to investigate the following three hypotheses:

1. There is no statistically significant positive linear correlation between reading comprehension and intrinsic reading motivation.

This main hypothesis is branched out into the following subhypotheses:

2. There is no statistically significant positive linear correlation between literal reading comprehension and reading motivation context between the scores obtained from both reading comprehension test and intrinsic reading motivation questionnaire. 
3. There is no statistically significant positive linear correlation between the scores obtained from both reading comprehension test and intrinsic reading motivation questionnaire inferential reading comprehension and intrinsic reading motivation in.

\section{Delimitations of the study:}

The study is delimitated to:

- Third year preparatory pupils at Fayoum governorate, Elmandara School.

- The following reading comprehension skills: (1) literal reading comprehension level including identifying the main idea, identifying supporting details and distinguishing between fact and opinion; (2) inferential reading comprehension level including guessing the meaning of unfamiliar words through context, predicting and recognizing time and spatial sequences.

- Intrinsic reading motivation do mains including reading efficacy reading challenge, reading curiosity and reading involvement 


\section{Definitions of terms}

\section{Reading comprehension}

- Woolley (2011) defines Reading comprehension as the process of making meaning from text. The goal, therefore, is to gain an overall understanding of what is described in the text rather than to obtain meaning from isolated words or sentences.

- Bogota (2016) explained that reading comprehension at various levels is the product of reading and these levels are: literal level which occurs in "the lines" and involves the factual information that the reader find in the text, inferential level which is related to imply and mean further than what is actually written, critical level which means being able to appraise what is reading.

- For the purpose of this study, the researcher defines reading comprehension operationally as" the third year prep students ability to extract meaning from a text at three levels; literal level that involves the student's ability to understand the explicit information presented in a text, inferential level that involves the student's ability to go beyond the text and infer other details". 


\section{Reading motivation:}

Guthrie and Wigfield (2000) define it as reading motivation is the "individual's personal goals, values, and beliefs with regard to the topics, processes, and outcomes of reading" (p.405).

Intrinsic motivation for reading concerns "an individual's participation in reading for its own sake, and positive disposition toward engaging in reading activity"(Guthrie \& Wigfield، 2005, p.190)

\section{Review of literature}

Reading motivation can be categorized into two main categories and under each category there are a number reading motivation domains. These two main categories are intrinsic and extrinsic reading motivations (Froiland et al., 2012).

The first main subcategory is extrinsic motivation. Extrinsically motivated readers have their motivation originating from any benefit they gain for doing the activity, rather than from inside themselves because extrinsic motivation is doing an action for an external reward (Deci \& Ryan, 2000).

Intrinsic motivation for reading concerns "an individual's participation in reading for its own sake, and positive disposition toward engaging in reading activity"(Guthrie \& Wigfield، 2005, p.190). The first dimension in this category is self-efficacy defined by Zimmerman (2000) as the beliefs individuals hold 
about their ability to achieve a task or have. The second dimension of reading motivation is challenge. Challenge is rather associated to individuals' competence rather than beliefs about their efficacy (Deci \& Ryan, 2000). The third dimension in the intrinsic motivation subcategory is curiosity. Reading curiosity can be defined as "readers' eagerness and readiness to explore the world and acquire perspectives and ideas through reading about both interesting and involving topics" (Guthrie et al., 2000, p.334). The fourth dimension of intrinsic motivation for reading is Involvement. Reading involvement can be defined as individuals' "focus on trying to learn whatever the task is designed to teach them" (Brophy, 2004, p.9).

Reading comprehension is a process by which a reader reconstructs a message encoded by a writer in graphic language (Saricoban, 2002). If we analyze this definition we will get that the reader has an input which is graphic language and has an output which is meaning. In more simple words we can consider reading comprehension process as a machine by which graphic language (input) is transformed to meaning (output).

Comprehension resembles a building process: You need bricks (identification of litters, words and sentences), you need concrete (mental connections); building tools (strategies) and a lot of other things Comprehension depends on knowledge that cannot always be found in a single word or sentence. "The products of comprehension are indicators of what the reader knows and understands after reading is completed, whereas the processes of comprehension are those cognitive activities by which the reader arrives at those products" (Rapp el. al., 2007, p.291). 
Reading comprehension is a complex interaction among automatic and strategic cognitive processes that enables the reader to create a mental representation of the text (Broek \& Espin, 2012). Comprehension depends not only on characteristics of the reader, such as prior knowledge and working memory, but also on language processes, such as basic reading skills, decoding, vocabulary, sensitivity to text structure, inferencing, and motivation. Comprehension also requires effective use of strategic processes, such as metacognition and comprehension monitoring. As readers mature in their comprehension skills, they are able to progress efficiently from the stage of learning to read to the ultimate goal of reading to learn (Yovanoff el al., 2005).

Research has primarily investigated language comprehension at the level of words and sentences. Sentence comprehension requires several constituent processes, such as identifying letters and sounds, binding those segments into words and clauses, and parsing the sentence into a meaningful description of some event. Reading comprehension, therefore, requires much more than processing a series of individual sentences (Traxler \& Gernsbacher, 2006).

\section{Materials and Method}

The current study investigated the relationship between reading comprehension and intrinsic reading motivation the procedures detailed below to investigate. The literature reviewed helped in enlightening the researcher in conducting the study procedures and in designing the tools of the study. 


\section{Subjects}

Participants of the study are randomly selected intact third year preparatory class at Fayoum governorate, Elmandara School; of whom 28 are girls and 12 are boys.

\section{Instruments}

\section{Reading comprehension test}

\section{Objectives of the test}

The test aimed at measuring and comparing students' performance in reading comprehension skills.

\section{Description of the test}

It consisted of 6 passages followed by a number of multiple choice questions aimed at testing the following reading comprehension skills: identifying the main idea of a context, identifying supporting details of a context, distinguishing between fact and opinion, recognizing time and spatial sequences, guessing the meaning of unfamiliar words through context, predicting some events in a context based on contextual clues and indicators, recognizing similarities and differences, identifying irrelevant ideas in terms of meaning, identifying irrelevant ideas in terms of time.

\section{Instructions of the pre and post tests}

The test instructions were clear and simple in order to be easily understood by students. Students were asked to underline the right answer. The time for taking the test was 90 minutes and total mark was 36. Instructions for this test included:

- Read every passage very carefully and try to understand it then answer the questions that follow by choosing the correct answer for each question. 
- When answering a question read all the available answers and then choose the correct one.

- Answer all the questions and do not leave any question without an answer.

\section{Key answers for the test}

The test consisted of 36 multiple choice questions. Each question has four answers. Only one of them is the right one. One mark for each right answer of the four answers. The total mark is 36 .

\section{Validity of the test}

A valid test is one that measures what is intended to measure (Perry, 2005). In order to ensure the validity of the test, a group of Jury members were requested to express their point of view concerning the following:

1- The suitability of the reading passages for student's level.

2- The extent to which each item measured the intended skill. Following the feedback of the jury committee, some modifications were made in the final version of the test, for example some passages were shortened.

\section{Piloting of the test}

A pilot study of both tests was conducted before applying the experiment. The test was piloted on 40 students of third year preparatory students, Elmandara School who were randomly selected.

\section{Calculating of the test time}

The time spent by each student in order to answer the pre and post tests questions during exploratory application was observed. In calculating the arithmetic mean of the time taken by the 
students of the exploratory application, the time to answer the test questions was one hour and a half.

\section{Reliability of the test}

The reliability of both tests was measured by applying KuderRichardson formula (K_R 20 Test) using SPSS because the test consisted of dichotomously multiple choices scored items with a range of difficulty. The reliability coefficient of the pretest was 0.811. Therefore, the test was considered highly reliable.

\section{Reading Motivations Questionnaire}

\section{Objectives of Reading Motivations Questionnaire}

The proposed reading motivations questionnaire was researcherdesigned on the light of Wigfield and Guthrie (1997). It aimed at measuring and comparing students' reading motivation rate before and after applying the program.

\section{Type of Method:}

It is student ratings of various aspects of their reading motivations.

\section{Scoring/ Reporting:}

The response format for the above items is $1=$ very different from me to $4=$ a lot like me. Scores are computed for each aspect and construct by averaging across their respective items. 


\section{Domains Measured:}

Reading motivations questionnaire contains 20 items intended to reflect 11 constructs of reading motivation. The domains measured are as follows:

1. Reading Efficacy ( 3 items) $=12$ marks

2. Reading Challenge $(5$ items $)=20$ marks

3. Reading Curiosity $(5$ items $)=20$ marks

4. Reading Involvement $(7$ items $)=28$ marks

\section{Instructions for Reading Motivations Questionnaire}

Questionnaire instructions were clear and simple in order to be easily understood by students. Students were asked to circle (1) If the statement is very different from you, circle (2) If the statement is a little different from you, circle (3) if the statement is a little like you and circle (4) If the statement is a lot like you.

\section{Instructions for this questionnaire include:}

- There is no right or wrong answer. If I asked you, "who likes sweets?" and some one answered, "I do," and the other said " I don't." both answers are right. 
- Read every item very carefully and try to understand it then choose the suitable answer that expresses you the most from $1,2,3$ or 4 .

- Answer all the questions and do not leave any question without an answer.

\section{Validity of the Reading Motivations questionnaire}

In order to ensure the validity of the test, a group of Jury members were requested to express their point of view concerning the following:

3- The suitability of the items for student's level.

4- The extent to which each item measured the intended motivational domains.

Following the feedback of the jury committee, some modifications were made in the final version of the questionnaire, for example some items were shortened. In some other cases, the researcher used other expressions for some items.

\section{Piloting Reading Motivations Questionnaire}

Piloting of the reading motivations questionnaire was conducted before carrying out the experiment. The test was piloted on 20 students of third year preparatory students, Elmandara School who were randomly selected. They were not the same students to whom the program was taught. The purpose of the pilot testing was to determine the following:

\section{Calculating time of Reading Motivations Questionnaire}

The time spent by each student in order to fill in the reading motivations questionnaire during exploratory application was 
observed. In calculating the arithmetic mean of the time taken by the students of the exploratory application, the time to answer the questionnaire questions was one hour and a half.

\section{Reliability of the Reading Motivations Questionnaire}

The reliability of reading motivations questionnaire was tested by applying Cronbach's alpha using SPSS. The reliability coefficient was 0.926 . Therefore, reading motivations questionnaire was considered highly reliable.

\section{Findings and Discussion}

The present study makes use of SPSS version 17 to calculate Pearson correlation coefficient, P-value and linear regression R2 of the scores obtained from both reading comprehension test and reading motivation questionnaire. The correlation coefficient is a number between -1 and +1 that determines whether two paired sets of data are related. The closer to 1 the more confident the researcher of a positive linear correlation (as one value goes up the other also goes up) and the closer to -1 the more confident we are of a negative linear correlation (as one goes up the other goes down). If the data from the study results in a p-value of less than that 0.05 , the researcher will claim that his study is significant and it enables him to reject the null hypothesis and conclude that a relationship really exists.

\section{Testing of the study hypotheses}

\section{Testing the main hypothesis}

Hypothesis one states that; "there is no statistically significant positive linear correlation between reading comprehension and intrinsic reading motivation between the scores obtained from 
both reading comprehension test and reading motivation questionnaire."

For testing the previous hypothesis, the researcher calculated Pearson correlation coefficient and P-value of the scores obtained from both reading comprehension test and reading motivation questionnaire. The results are shown in table (2) below:

\section{Table (1)}

Pearson correlation coefficient and P-value of the scores obtained from both reading comprehension test and reading motivation questionnaire

\begin{tabular}{|c|c|c|c|}
\hline \multicolumn{4}{|c|}{ Correlations } \\
\hline $\begin{array}{c}\text { Reading } \\
\text { motivation }\end{array}$ & $\begin{array}{l}\text { Reading } \\
\text { comprehension }\end{array}$ & & \\
\hline $.932^{* *}$ & 1 & $\begin{array}{c}\text { Pearson } \\
\text { Correlation }\end{array}$ & \multirow{3}{*}{$\begin{array}{l}\text { Reading } \\
\text { comprehension }\end{array}$} \\
\hline .000 & & Sig. (2-tailed) & \\
\hline 40 & 40 & $\mathrm{~N}$ & \\
\hline 1 & $.932^{* *}$ & $\begin{array}{c}\text { Pearson } \\
\text { Correlation }\end{array}$ & \multirow{3}{*}{$\begin{array}{l}\text { Reading } \\
\text { motivation }\end{array}$} \\
\hline & .000 & Sig. (2-tailed) & \\
\hline 40 & 40 & $\mathrm{~N}$ & \\
\hline
\end{tabular}

Table (1) shows that Pearson correlation of reading comprehension and reading motivation is $\left(.932^{* *}\right)$ and $\mathrm{P}$-value is 
(0.000). This indicates that we can reject the null hypothesis stating that "there is no statistically significant positive linear correlation between reading comprehension and reading motivation between the scores obtained from both reading comprehension test and reading motivation questionnaire" and shows that there is a significant clear positive linear correlation (as one value goes up the other also goes up) between reading comprehension and reading motivation. The coefficient of determination denoted R2 or "R squared" was calculated to show the proportion of the variance in the dependent variable that is predictable from the independent variable. The results are shown in figure (1) below:

\section{Figure (1)}

R2 calculated using linear regression of the scores obtained from both reading comprehension test and reading motivation questionnaire

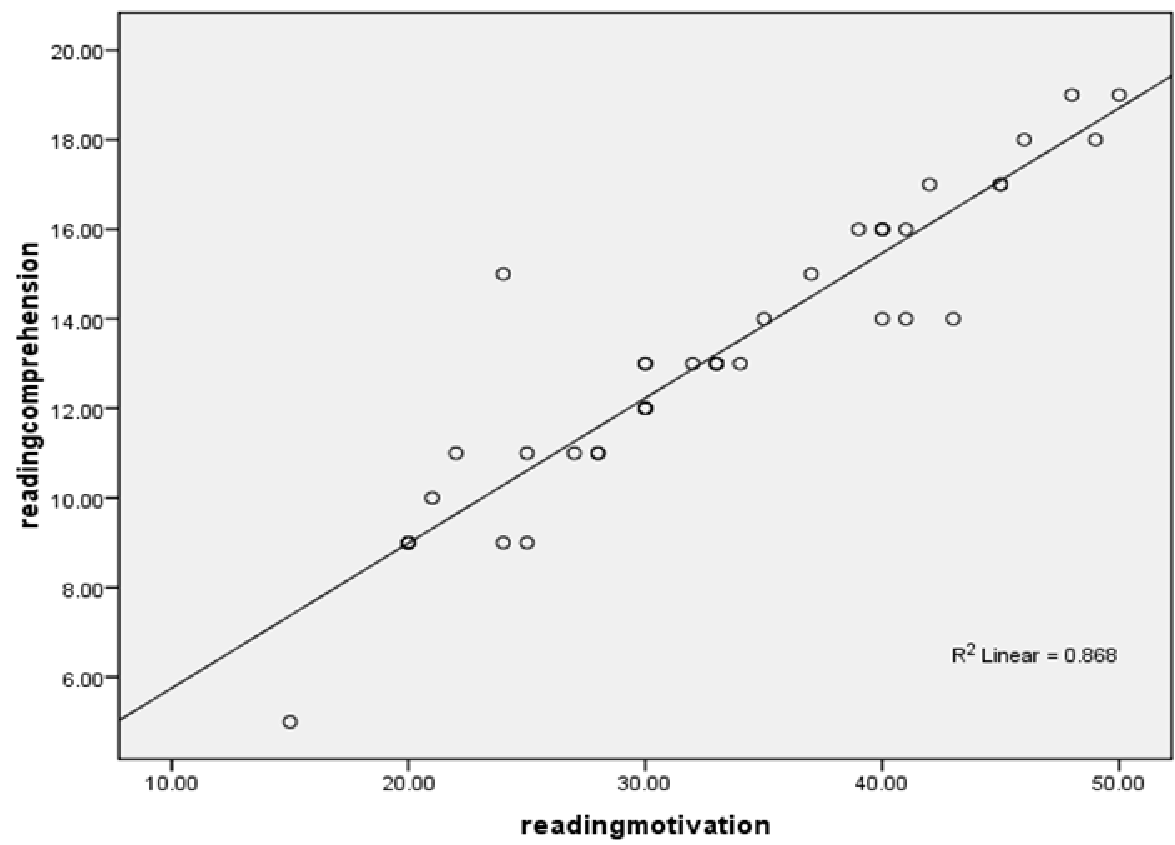


Figure (1) shows that R2 is (0.868) and hence it $\geq+0.70$, it indicates a very strong positive relationship. Therefore, we can say that the increase of reading comprehension scores predict the increase of intrinsic reading motivation.

\section{Testing the first sub-hypothesis hypothesis}

Hypothesis one states that; "there is no statistically significant positive linear correlation between literal reading comprehension and intrinsic reading motivation between the scores obtained from both reading comprehension test and intrinsic reading motivation questionnaire."

For testing the previous hypothesis, the researcher calculated Pearson correlation coefficient and P-value of the scores obtained from both literal reading comprehension sub-test and intrinsic reading motivation questionnaire. The results are shown in table (3) below: 


\section{Table (2)}

Pearson correlation coefficient and P-value of the scores obtained from both reading comprehension test and reading motivation questionnaire

\begin{tabular}{|c|c|c|c|}
\hline \multicolumn{4}{|c|}{ Correlations } \\
\hline $\begin{array}{l}\text { Literal Reading } \\
\text { comprehension }\end{array}$ & $\begin{array}{l}\text { Reading } \\
\text { motivation }\end{array}$ & & \\
\hline $.817^{* *}$ & 1 & $\begin{array}{l}\text { Pearson } \\
\text { Correlation }\end{array}$ & \multirow{3}{*}{ Reading motivation } \\
\hline .000 & & Sig. (2-tailed) & \\
\hline 40 & 40 & $\mathrm{~N}$ & \\
\hline \multirow[t]{2}{*}{1} & $.817^{* *}$ & $\begin{array}{c}\text { Pearson } \\
\text { Correlation }\end{array}$ & \multirow{3}{*}{$\begin{array}{l}\text { Literal Reading } \\
\text { comprehension }\end{array}$} \\
\hline & .000 & Sig. (2-tailed) & \\
\hline 40 & 40 & $\mathrm{~N}$ & \\
\hline
\end{tabular}

Table (2) shows that Pearson correlation between reading comprehension and reading motivation is $\left(.817^{* *}\right)$ and $\mathrm{P}$-value is (0.000). This indicates that we can reject the null hypothesis stating that "there is no statistically significant positive linear correlation between literal reading comprehension and reading motivation between the scores obtained from both reading comprehension test and reading motivation questionnaire" and shows that there is a significant clear positive linear correlation (as one value goes up the other also goes up) between literal reading comprehension and reading motivation. The coefficient of determination denoted R2 or "R squared" was calculated to 
show the proportion of the variance in the dependent variable that is predictable from the independent variable. The results are shown in figure (2) below:

\section{Figure (2)}

R2 calculated using linear regression of the scores obtained from both reading comprehension test and reading motivation questionnaire

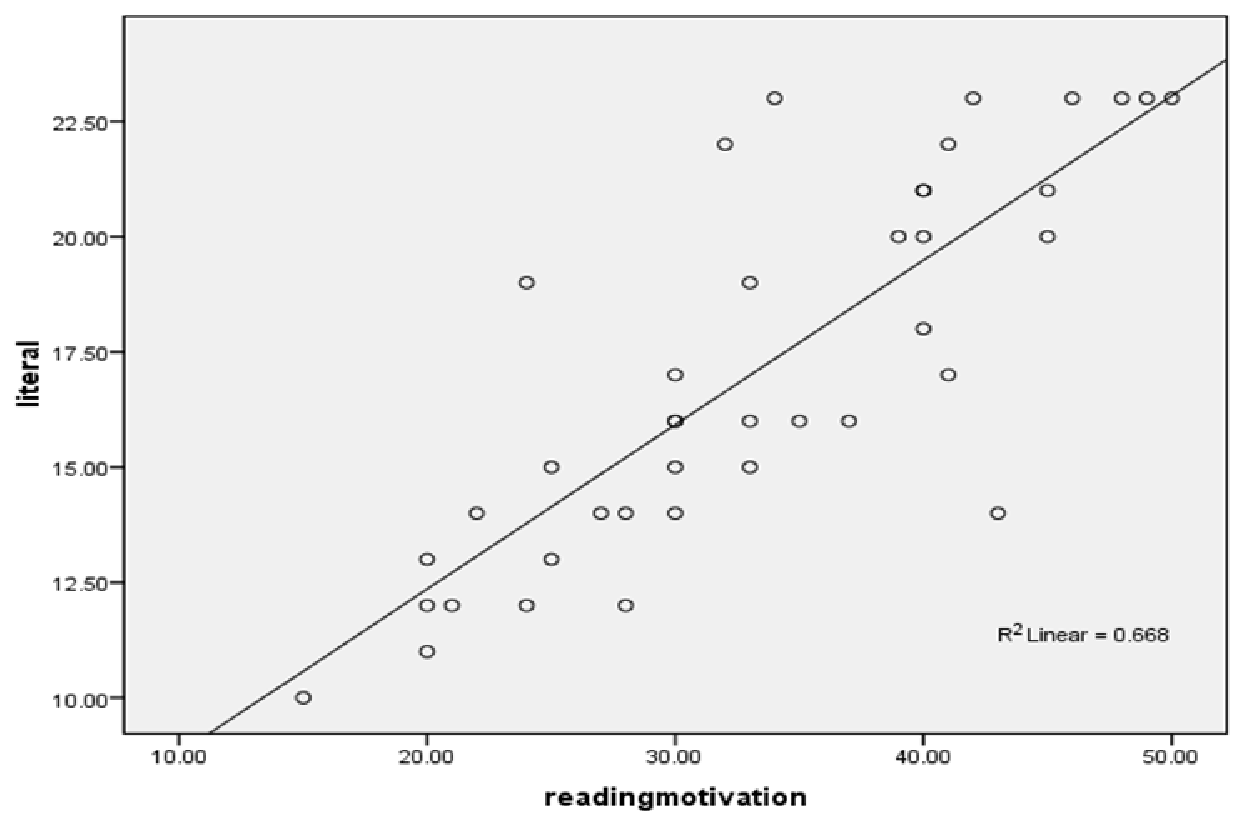

Figure (2) shows that R2 is (0.668) and hence it $\geq+040$, it indicates a strong positive relationship. Therefore, we can say that the increase of reading comprehension scores predict the increase of intrinsic reading motivation. 


\section{Testing the second sub-hypothesis hypothesis}

Hypothesis one states that; "there is no statistically significant positive linear correlation between inferential reading comprehension and intrinsic reading motivation between the scores obtained from both reading comprehension test and intrinsic reading motivation questionnaire."

For testing the previous hypothesis, the researcher calculated Pearson correlation coefficient and P-value of the scores obtained from both inferential reading comprehension test and intrinsic reading motivation questionnaire. The results are shown in table (3) below:

\section{Table (3)}

Pearson correlation coefficient and P-value of the scores obtained from both reading comprehension test and reading motivation questionnaire

\begin{tabular}{l|l|l|l}
\hline 40 & 40 & $\mathrm{~N}$ & \\
\hline 1 & $.889^{* *}$ & $\begin{array}{l}\text { Pearson } \\
\text { Correlation }\end{array}$ & $\begin{array}{l}\text { Inferential Reading } \\
\text { comprehension }\end{array}$ \\
\hline 40 & .000 & Sig. (2-tailed) & \\
\hline
\end{tabular}

**. Correlation is significant at the 0.01 level (2-tailed).

Sig. (2-tailed) 
Table (2) shows that Pearson correlation between reading comprehension and intrinsic reading motivation is $\left(.889^{* *}\right)$ and $\mathrm{P}$-value is (0.000). This indicates that we can reject the null hypothesis stating that "there is no statistically significant positive linear correlation between inferential reading comprehension and intrinsic reading motivation between the scores obtained from both reading comprehension test and reading motivation questionnaire" and shows that there is a significant clear positive linear correlation (as one value goes up the other also goes up) between inferential reading comprehension and reading motivation. The coefficient of determination denoted R2 or "R squared" was calculated to show the proportion of the variance in the dependent variable that is predictable from the independent variable. The results are shown in figure (3) below:

\section{Figure (3)}

R2 calculated using linear regression of the scores obtained from both reading comprehension test and reading motivation questionnaire 


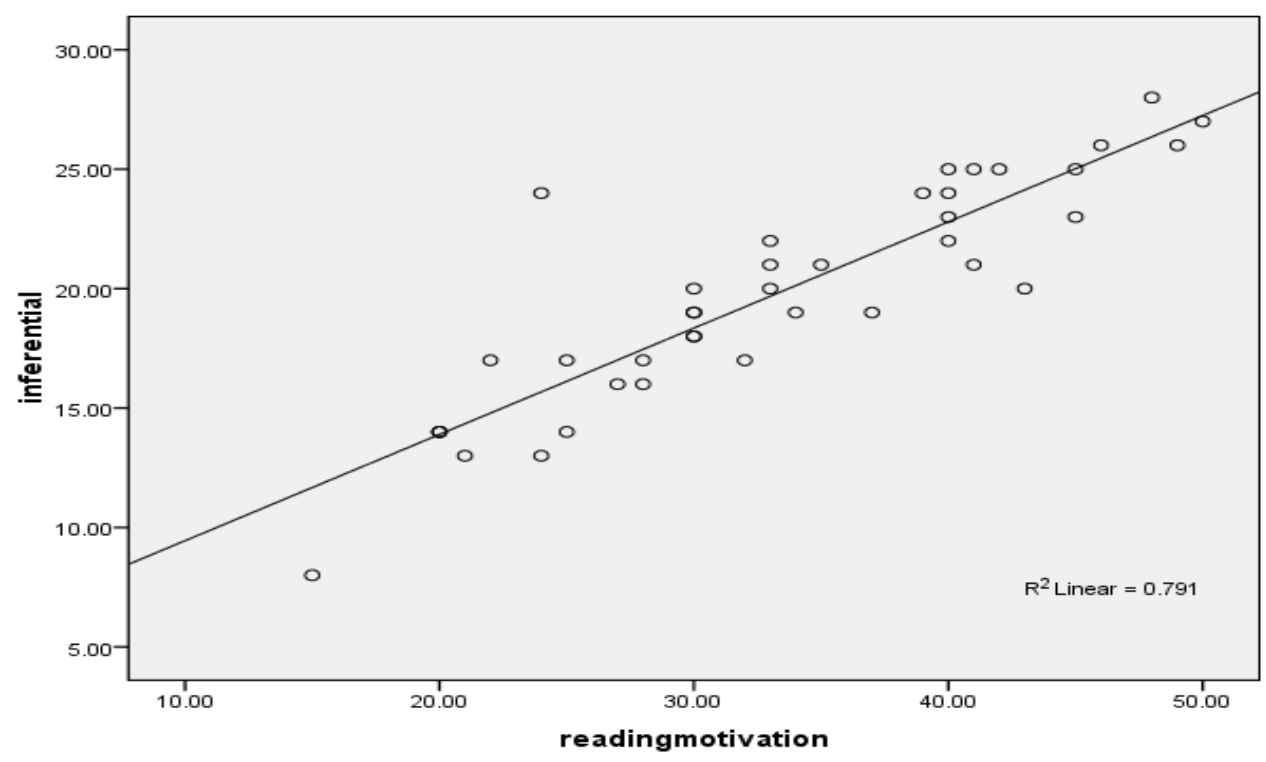

Figure (3) shows that R2 is $(0.791)$ and hence it $\geq 0.70$, it indicates a very strong positive relationship. Therefore, we can say that the increase of inferential reading comprehension scores predict the increase of intrinsic reading motivation.

\section{Discussion}

Results of the current study indicate there is a very strong positive relationship between reading comprehension and intrinsic reading motivation. Therefore, we can say that the increase of reading comprehension scores predict the increase of intrinsic reading motivation. Results also show that there is a strong positive relationship between reading comprehension and intrinsic reading motivation. Therefore, we can say that the increase of literal reading comprehension scores predict the increase of intrinsic reading motivation. These findings are in line with (Takaloo \& Ahmadi, 2017) that asserted the existence of a correlation between reading comprehension and reading 
motivation. Results also show that there is a very strong positive relationship between inferential reading comprehension and intrinsic reading motivation. Therefore, we can say that the increase of literal reading comprehension scores predict the increase of intrinsic reading motivation. It is also clear that the positive linear correlation between literal comprehension and intrinsic reading motivation is less than that between inferential reading comprehension and intrinsic reading motivation. It can be assumed that the more competency the student has in reading comprehension, the more he became intrinsically motivated to read more and more and became involved in reading activities.

\section{Recommendations}

In the light of the study results, the researcher recommends the following:

Students' reading comprehension should be given top priority in reading instruction due to the primary role of this ability in educating a learned society.

Curriculum designers should focus on approaches that are directed to all levels of reading comprehension.

Teachers should develop ways that may improve reading comprehension and make students motivated. 


\section{$\underline{\text { References }}$}

Becker, M., McElvany, N., \& Kortenbruck, M. (2010). Intrinsic and extrinsic reading motivation as predictors of reading literacy: A longitudinal study. Journal of Educational Psychology, 102(4), 773-785.

Bogota, D.,C. (2016). The Theory of the Six Readings: Promoting Reading Comprehension in English as a foreign Language. Unpublished M.A. thesis, Faculty of Education, Universidad Libre.

Broek, P., \& Espin, C. (2012). Connecting cognitive theory and assessment: Measuring individual differences in reading comprehension. School Psychology Review, 41, 315-325 .

Brophy, J. (2004). Motivating Students to Learn. Second Edition. Mahwah, New Jersey: Lawrence Erlbaum Associates.

Brophy, J. (2010). Motivating students to learn (3rd ed.) Madison Avenue, Ny: Routledge.Byrne, D.C (1971): English teaching extracts, Longman group limited, England.

Cambria, J., Guthrie,J. (2010). Motivating and engaging students in reading, The NERA Journal, 46 (1), 16-29.

Deci, E. L., \& Ryan, R. M. (2000). The "What" and "Why" of Goal Pursuits: Human Needsand the Self-Determination of Behavior. Psychological Inquiry, 11(4), 227-268.

Froiland, J. M., Oros, E., Smith, L., \& Hirchert, T. (2012). Intrinsic motivation to learn: The nexus between 
psychological health and academic success.

Contemporary School Psychology, 16(1), 91-100.

Guthrie, J. T., \& Wigfield, A. (2000). Engagement and motivation in reading. In M. L. Kamil, P. B. Mosenthal, P. D. Pearson, \& R. Barr (Eds.), Reading research handbook, 3, 403- 424.

Guthrie, J. T., \& Wigfield, A. (2005). Roles of Motivation and Engagement in Reading Comprehension Assessment. In Scott G. Paris \& Steven A. Stahl (Eds.), Children's Reading Comprehension and Assessment (pp.187-213). Mahwah, New Jersey: Lawrence Erlbaum Associates.

Guthrie, J. T., Wigfield, A., \& VonSecker, C. (2000). Effects of Integrated Instruction on Motivation and Strategy Use in Reading. Journal of Educational Psychology, 92(2), 331341.

Jafari, S. M., \& Shokrpour, N. (2012). EAP students, reading motivation of English academic expository texts: A mixed methods design. International Journal of Linguistics, 4(4), 372-392.

Logan, S., Medford, E., \& Hughes, N. (2011). The importance of intrinsic motivation for high and low ability readers' reading comprehension performance. Learning and Individual Differences, 21(1), 124-128.

Mermelstein, A. D. (2014). Improving EFL learners' reading levels through extensive reading. The Reading Matrix, 14(2), 227-242.

Mohammadian, A., Saed,A. \& Shahi,Y. (2017). The Effect of Using Video Technology on Improving Reading 
Comprehension of Iranian Intermediate EFL Learners, ALLS, 9(2):17-23.

Rapp, D., N. van den, B.P., Kristen L. Christine, A. E. Panayiota, K., M. (2007). Higher-Order Comprehension Processes in Struggling Readers: A Perspectivefor Research and Intervention, Scientific Studies of Reading, 11(4), 289-312.

Saricoban, A. (2002). Reading Strategies of Successful Readers Through The Three Phase Approach, The Reading Matrix, 2(3), 1-16.

Schaffner, E., \& Ulferts, H. (2013). Reading amount as a mediator of the effects of intrinsic and extrinsic reading motivation on reading comprehension. Reading Research Quarterly, 48(4), 369-385.

Takaloo, N., M. \& Ahmadi, M. R. (2017). The Effect of Learners' Motivation on Their Reading Comprehension Skill: A Literature Review, International Journal of Research in English Education, 2(3), 10-21.

Tohidi H. \& Jabbari, M. (2012). The effects of motivation in education, Procedia - Social and Behavioral Sciences 31, $820-824$.

Traxler, M. J., \& Gernsbacher, M. A. (2006). Handbook of psycholin guistics (2nd Ed.). San Diego, California: Academic Press.

Woolley, G. (2011) Reading Comprehension: Assisting children with learning difficulties, Netherlands: Springer.

Yovanoff, P., Duesbery, L., Alonzo, J., \& Tindal, G. (2005). Grade-level invariance of a theoretical causal structure predicting reading comprehension with vocabulary and 
oral reading fluency. Educational Measurement: Issues and Practice, 24(3), 4-12.

Zimmerman, B. J. (2000). Self-efficacy: An essential motive to learn. Contemporary Educational Psychology, 25 (1), 8291. 